Archived version from NCDOCKS Institutional Repository http://libres.uncg.edu/ir/asu/

\title{
Appalachỉan
}

B O O N E, N O R T H C A R O L I N A

\section{Students At Risk Of Being Marked On By Peers Due To Alcohol Poisoning: An Exploratory Study}

\author{
By: Christopher M. Seitz, Muhsin Michael Orsini, and Martin P. Davoren
}

\begin{abstract}
This study explored the behavior of bystanders at parties who use markers to draw on intoxicated college students who show symptoms of alcohol poisoning, rather than helping those students. Half (50\%) of the study's 111 students reported being at a party where an intoxicated college student was drawn on with markers while passed out. The most common sign of alcohol poisoning observed was that the person could not be roused (63\%). The most common location of drawings was the face $(89 \%)$ and common items drawn were genitals (59\%) and profanity (45\%). The personal and legal ramifications of this is discussed.
\end{abstract}

Seitz, Christopher M.; Orsini, Muhsin Michael; Davoren, Martin P. 2017 STUDENTS AT RISK OF BEING MARKED ON BY PEERS DUE TO ALCOHOL POISONING: AN EXPLORATORY STUDY. The Free Library (September, 22), https://www.thefreelibrary.com. Publisher version of record available at: https:// www.thefreelibrary.com/STUDENTS+AT+RISK+OF+BEING+MARKED+ON+BY+PEERS+DUE+TO +ALCOHOL...-a0536388692 


\title{
STUDENTS AT RISK OF BEING MARKED ON BY PEERS DUE TO ALCOHOL POISONING: AN EXPLORATORY STUDY
}

\author{
Christopher M. Seitz, DrPH, MPH \\ Muhsin Michael Orsini, EdD \\ Martin P. Davoren, PhD
}

\begin{abstract}
This study explored the behavior of bystanders at parties who use markers to draw on intoxicated college students who show symptoms of alcohol poisoning, rather than helping those students. Half (50\%) of the study's 111 students reported being at a party where an intoxicated college student was drawn on with markers while passed out. The most common sign of alcohol poisoning observed was that the person could not be roused (63\%). The most common location of drawings was the face (89\%) and common items drawn were genitals (59\%) and profanity (45\%). The personal and legal ramifications of this is discussed.
\end{abstract}

Keywords: alcohol, college, university, students

\section{INTRODUCTION}

Binge drinking among college students is a major public health concern that can result in a variety of negative health problems, including alcohol poisoning. Various national surveys suggest that roughly $30 \%$ of college students binge drink (American College Health Association, 2016; Johnston, O’Malley, Bachman, Schulenberg, \& Miech, 2016). This is alarming, as an overwhelming amount of literature indicates that binge drinking is strongly associated with a variety of negative health issues, such as poor academic performance, assault (physical and sexual), unsafe sexual behaviors, suicide attempts, drunk driving, property damage, and memory loss (Ham \& Hope, 2003; White \& Hingson, 2014).

Perhaps the most concerning negative health issue associated with binge drinking is alcohol poisoning, which can lead to death. In 2008 alone, over 58,000 college-aged students were hospitalized for alcohol poisoning (White, Hingson, Pan, \& Yi, 2011). Alcohol poisoning takes place when a large dose alcohol is consumed, which can depress the nerves responsible for involuntary movement, such as breathing, and lead to death (National Institute on Alcohol Abuse and Alcoholism, 2015). The warning signs of alcohol poisoning include: mental confusion, stupor, coma, not being able to be roused, vomiting, seizures, slow breathing (less than eight breaths per minute), irregular breathing (10 or more seconds between breaths), and signs of hypothermia (e.g., low body temperature, bluish skin color, paleness) (National Institute on Alcohol Abuse and Alcoholism, 2015).

Regardless of alcohol poisoning's consequences and telltale signs, the peer-reviewed lit- erature and anecdotal evidence suggest that intoxicated college students who show symptoms of alcohol poisoning are subject to being drawn on by bystanders with markers and pens as a humorous prank, rather than being helped. To the authors' knowledge, the only peer-reviewed publication mentioning this behavior is Workman's (2001) qualitative study exploring the meaning of college drinking. In his study, fraternity members briefly describe using permanent markers to draw on the faces of intoxicated party-goers who are unresponsive (Workman, 2001).

Non peer-reviewed publications also describe this behavior. News articles from 2004 and 2007 describe the alcohol poisonings and tragic deaths of fraternity members at two different colleges. As they were dying from alcohol poisoning, their friends used markers to draw slurs and profane sexual content all over their bodies (e.g., face, torso, and extremities) (ABC 7 News Denver, 2004; CBS News, 2007). This same type of behavior is also shown in social media. For example, the website www.passedoutphotos.com is dedicated to sharing and hosting photographs of intoxicated people that have been manipulated by others (e.g., drawn on with markers, wrapped in plastic, stripped of clothing). In addition, the smartphone application "Drunk Sharpie Attack" allows someone to take a photograph of a person and use a digital pen to draw content on the photograph, simulating the action of drawing on an intoxicating, unresponsive person (Mac Users Guide, 2010).

Given the importance of alcohol poisoning and the dearth of relevant peer-reviewed research regarding those at risk of alcohol poisoning being drawn on by bystanders, it is critical to explore

Corresponding author: Christopher M. Seitz, DrPH, MPH, Assistant Professor, Appalachian State University, Department of Health \& Exercise Science , Holmes Convocation Center , 111 Rivers Street, PO Box 32071, Boone, NC 28608, seitzcm@appstate.edu 
the prevalence and characteristics of this behavior among college students. By gaining more knowledge on this subject, campus health professionals can begin to learn how to prevent it from happening in the future. As such, we conducted an exploratory study among college students to determine how often this behavior takes place, how often intoxicated students being drawn on are at risk of alcohol poisoning, and the characteristics of the content that is drawn on students' bodies.

\section{METHODS}

Participants were enrolled in a general education course titled "Drugs and Society" at a large, public university in the Northwest/Midwest region of the United States. Although the course was required for all Community Health majors, it was open to students of all majors as an elective. A total of 180 students were invited to participate in this research study, of which 111 (62\%) agreed to complete an anonymous paper and pencil questionnaire. Most participants identified themselves as female $(78 \%)$ and ranged in age from 18 to 22 or more years $(M=20.0, S D=1.46)$, as shown in Table 1.

This research study was approved by the Institutional Review Board of the host institution. Participants were invited to complete the questionnaire during a regular class meeting, with no consequences for agreeing or declining to participate (Appendix 1).

After reporting demographic information, participants responded to multiple items regarding the frequency of observing intoxicated college students who were drawn on by peers with markers or pens. In addition, participants reported signs of alcohol poisoning and the location and content of what was drawn on the intoxicated student during their last observation. This information was gathered by inviting participants to draw what they observed on a silhouette form of a human body on the questionnaire (Appendix 1).

Descriptive statistics were used to summarize demographic information, frequencies of observations, and the signs of alcohol poisoning. The location and content of what was drawn on the silhouette was categorized into different themes. Contingency table analysis using the Chi-square statistic was used to determine if the observations were independent of sex. An independent sample t-test was used to determine if the observations were independent of age.

\section{RESULTS}

About half of the participants ( $\mathrm{n}=57$, $51 \%$ ) reported they had been at a party where an intoxicated college student was drawn on with markers or pens while sleeping or passed out. These participants observed the behavior 1 to 10 times during their time at college $(\mathrm{M}=3.0, \mathrm{SD}$ $=2.17, \mathrm{Mdn}=2$ ). During the current semester, these participants observed the behavior 1 to 2 times $(\mathrm{M}=0.63, \mathrm{SD}=0.73)$. The most common signs of alcohol poisoning observed by participants were: person cannot be roused, mental confusion, stupor, and vomiting (Table 2).

The most common locations of drawings on intoxicated college students were the face and arms (Table 3). Five themes emerged from the content of drawings on intoxicated college students: (1) Genitals (which were almost exclusively male genitals), (2) Profanity, (3) Scribbles (i.e., random markings), (4) Images (e.g., mustaches, eyebrows, tear drops, heart shapes), and (5) Words other than profanity. The most common content of drawings were Genitals, Profanity, and Images (Table 4).

Contingency table analysis indicated that the frequency of observing an intoxicated college student being drawn on by peers in the current semester was not independent of sex, $\bigotimes 2(1, n=111)$ $=2.01, \mathrm{p}=0.045$. Specifically, male participants reported observing the behavior more frequently in the current semester than females $(\mathrm{M}=0.94$, $0.49 ; \mathrm{SD}=0.83,0.64$ respectively), as shown in Table 5 .

An analysis of variance indicated that the frequency of observing an intoxicated college student being drawn on by peers in the current semester was not independent of age, $\mathrm{F}(4,56)=5.70$, $\mathrm{p}<0.001$ (two-tailed). Specifically, participants of less than legal drinking age (20 years or less) reported observing the behavior more frequently in the current semester than others $(\mathrm{M}=0.88,0.26$; $\mathrm{SD}=0.78,0.45$ respectively), as shown in Table 6 .

Table 1. Age and sex of participants

\begin{tabular}{lccc}
\hline Age & Female & Male & Total \\
\cline { 2 - 4 } 18 & 12 & 9 & 21 \\
\hline 19 & 21 & 6 & 27 \\
20 & 18 & 4 & 22 \\
21 & 12 & 1 & 13 \\
22 or older & 24 & 4 & 28 \\
Total & 87 & 24 & 111
\end{tabular}


Table 2. Frequency of observed signs of alcohol poisoning

\begin{tabular}{lcc}
\hline Sign & $n$ & $\%$ \\
\cline { 2 - 3 } Person cannot be roused & 35 & 63 \\
\hline Mental confusion & 30 & 54 \\
Stupor & 30 & 54 \\
Vomiting & 18 & 32 \\
Hypothermia & 1 & 2 \\
Irregular breathing & 1 & 2 \\
Coma & 0 & 0 \\
Seizures & 0 & 0 \\
Slow breathing & 0 & 0 \\
None of the above & 2 & 4 \\
Total & 117 & 100
\end{tabular}

Table 3. Locations of drawings on intoxicated students

\begin{tabular}{lcc}
\hline Location & $n$ & $\%$ \\
\cline { 2 - 3 } Face & 50 & 89 \\
\hline Arm & 25 & 45 \\
Chest & 10 & 18 \\
Leg & 6 & 11 \\
Back & 3 & 5 \\
Total & 94 & 100
\end{tabular}

Table 4. Content of drawings on intoxicated students

\begin{tabular}{lcc}
\hline Content & $n$ & $\%$ \\
\cline { 2 - 3 } Genitals & 33 & 59 \\
\hline Profanity & 25 & 45 \\
Image & 18 & 32 \\
Scribble & 10 & 18 \\
Word/s & 10 & 18 \\
Total & 96 & 100
\end{tabular}


Table 5. Frequency of observing an intoxicated student being drawn on by peers and the sex of the observer

\begin{tabular}{lccc}
\hline Observations & Female & Male & Total \\
\cline { 2 - 4 } 0 & 23 & 6 & 29 \\
\hline 1 & 13 & 6 & 19 \\
2 & 3 & 5 & 8 \\
Total & 39 & 17 & 56
\end{tabular}

Table 6. Frequency of observing an intoxicated student being drawn on by peers and the age of the observer

\begin{tabular}{lcccccc}
\hline Observations & 18 & 19 & 29 & 21 & 22 or older & Total \\
& & & & & & \\
\cline { 2 - 7 } 0 & 1 & 8 & 3 & 6 & 11 & 29 \\
\hline 5 & 5 & 6 & 2 & 1 & 5 & 19 \\
2 & 1 & 3 & 0 & 0 & 8 \\
Total & 10 & 15 & 8 & 7 & 16 & 56
\end{tabular}

\section{DISCUSSION}

This study aimed to explore characteristics of students at risk of alcohol poisoning who are drawn on from a convenience sample of students at a large university. It found that this behavior was common with half of the participants reporting that they had been at a party where an intoxicated college student was drawn on with markers or pens while sleeping or passed out.

The health and legal ramifications are substantial for drawing on intoxicated college students who show symptoms of alcohol poisoning. First, students who are intoxicated may be at risk of alcohol poisoning and death (National Institute on Alcohol Abuse and Alcoholism, 2015) and should be helped, rather than drawn on by bystanders. Second, family members and friends may experience despair not only from the loss of a loved one who died from alcohol poisoning, but also from seeing profanity drawn on their dead body (ABC 7 News Denver, 2004; CBS News, 2007). Third, those who draw on students exhibiting symptoms of alcohol poisoning could face legal issues, such as battery or assault, and could have long-term consequences on an individual student's career prospects and personal life.

The findings from this exploratory study suggest that bystander educational training may be necessary to address this health issue at colleges. This study's findings reflects that of previous research, suggesting that colleges educate students about the warning signs of alcohol poisoning and provide a road map for students to implement in the emergency of someone exhibiting signs of poisoning, as many students do not know the warn- ing signs and are less likely to help others if they do not view the signs of poisoning as an emergency (Haas \& Flores, 2012; Krieger, Serrano, \& Neighbors, 2017; OsterAaland, Lewis, Neighbors, Vangsness, \& Larimer, 2009). This research indicates that educational efforts should not only include recognition of poisoning and how to medically intervene, but should also include the unethical legalities of drawing on an unresponsive person.

College students are at a point of significant transition. Surrounded by peers, many of whom are living away from home for the first time, university students experience freedom from parental control. In developing their identity, peer friendships are vital. They provide socialization opportunities for the individual. Alcohol is part of the university culture, present at many social functions and part of many social interactions. In fact, students view their university experience as an opportunity to drink excessively before assuming the responsibilities of adulthood (Borsari \& Carey, 2006). Students often occupy a culture of unrealistic optimism, failing to recognize the reality in their lived experience (Clarke, Lovegrove, Williams, \& Machperson, 2000). By educating a campus community about the dangers of alcohol poisoning and how to respond as a bystander, colleges can help students be informed, responsible members of a community and provide guidance for students as they navigate the transitions involved with being at college.

This exploratory study has limitations. First, it reports on a small, convenient sample size. At the same time, however, it yields a unique in- 
sight into this commonplace phenomenon across the university system. Furthermore, it highlights areas for health promotion interventions with this vulnerable population. Second, results from this study are not generalizable. However, they are consistent with anecdotal evidence in the field and signal the prevalence of this behavior in a university student population. There is a need for further research, employing a larger sample size across different institutions to investigate university student partygoers' habits, behaviors and attitudes.

\section{References}

ABC 7 News Denver. (2004, October 8). Frat brothers scrawled slurs all over CU student's body: Gordie Bailey's family considers suing. Retrieved from http:/www.thedenverchannel.com/news/ frat-brothers-scrawled-slurs-all-over-cu-student-sbody

American College Health Association. (2016). American College Health Association-National College Health Assessment II: Reference Group Executive Summary Spring 2016. Hanover, MD: American College Health Association.

Borsari, B., \& Carey, K.B. (2006). How the quality of peer relationships influences college alcohol use. Drug and alcohol review, 25(4), 361-370.

CBS News. (2007, January 10). Dead frat pledge's body defaced. Retrieved from http://www.cbsnews.com/news/dead-frat-pledges-body-defaced/

Clarke, V.A., Lovegrove, H., Williams, A., \& Machperson, M. (2000). Unrealistic optimism and the health belief model. Journal of Behavioral Medicine, 23(4), 367-376.

Ham, L. S., \& Hope, D. A. (2003). College students and problematic drinking: A review of the literature. Clinical Psychology Review, 23(5), 719-759.

Haas, A., \& Flores, S. (2012). College student awareness of signs of alcohol poisoning. Journal of Alcohol and Drug Education, 56(3), 59-76.

Johnston, L.D., O’Malley, P.M., Bachman, J.G., Schulenberg, J.E. \& Miech, R.A. (2016).

Monitoring the Future national survey results on drug use, 1975-2015: Volume II, College students and adults ages 19-55. Ann Arbor, MI: Institute for Social Research, the University of Michigan.

Krieger, H., Serrano, S., \& Neighbors, C. (2017). The role of self-efficacy for bystander helping behaviors in risky alcohol situations. Journal of College Student Development, 58(3), 451-456.

Mac Users Guide (2010). Drunk Sharpie ATTACK! iPhone App. Retrieved from http://www.macusersguide.com/reviews/ iphone-app-review-drunk-sharpie/

National Institute on Alcohol Abuse and Alcoholism. (2015). A word about alcohol poisoning. Retrieved from http://www.niaaa.nih.gov/ alcohol-poisoning

OsterAaland, L., Lewis, M. A., Neighbors, C., Vangsness, J., \& Larimer, M. E. (2009). Alcohol poisoning among college students turning 21: Do they recognize the symptoms and how do they help? Journal of Studies on Alcohol and Drugs, (s16), 122130.

White, A.M., Hingson, R.W., Pan, I.J., Yi, H.Y. (2011). Hospitalizations for alcohol and drug overdoses in young adults ages 18-24 in the United States, 1999-2008: Results from the Nationwide Inpatient Sample. Journal of Studies on Alcohol and Drugs, 72(5), 774-786.

White, A., \& Hingson, R. (2014). The burden of alcohol use: Excessive alcohol consumption and related consequences among college students. Alcohol Research: Current Reviews, 35(2), 201-218.

Workman, T.A. (2001). Finding the meanings of college drinking: An analysis of fraternity drinking stories. Health Communication, 13(4), 427-447. 
Appendix 1. Questionaiire.

What is your sex?

Male Female

How old are you?

$\begin{array}{lllll}18 & 19 & 20 & 21 & 22 \text { or older }\end{array}$

Have you ever been at a party where a drunk college student was drawn on with markers or pens while sleeping/passed out?

Yes No

During your time as a college student, how many times have you witnessed a drunk college student being drawn on with markers or pens while they were sleeping/passed out? times

How many times have you witnessed this during this semester? times

The last time you witnessed a drunk college student being drawn on with markers/pens while they were sleeping/passed out, did the drunk person show any of the following signs? (Check all that apply)

Mental confusion

Stupor (not thinking normally)

Coma

Person cannot be roused (woken up)

Vomiting

Seizures

Slow breathing (fewer than eight breaths per minute).

Irregular breathing (10 seconds or more between breaths).

Hypothermia (low body temperature), bluish skin color, paleness

None of the above

To the best of your memory, please draw in detail what you saw the last time you witnessed a drunk college student being drawn on with markers/pens while they were sleeping/passed out:

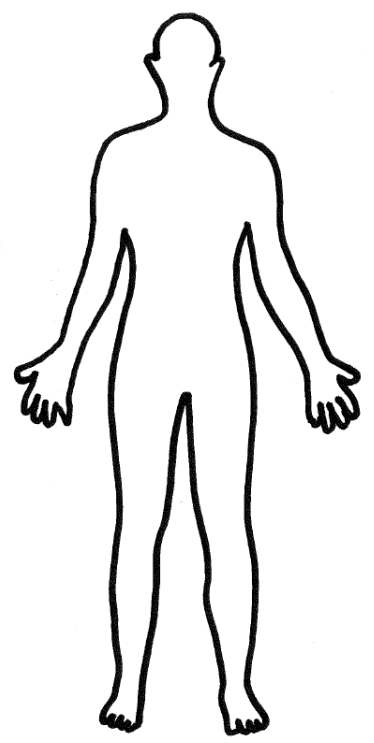

